\title{
Impact of vocational training on older workers' employment
}

\author{
E.S. Lapshova ${ }^{1 *}$, and $V . V$. Levchenko ${ }^{2}$ \\ ${ }^{1}$ Samara National Research University, Samara, Russia \\ ${ }^{2}$ Samara National Research University, Samara, Russia
}

\begin{abstract}
The object of this research is the vocational training of older workers. The purpose is to analyze the impact of vocational training on older workers' employment. The research methods are theoretical, general scientific and empirical methods; diagnostic, statistical methods, etc. Theoretical and practical results are the following: the vocational training of older workers is an important factor in their employment. The low coverage of older workers participating in vocational training can be overcome by popularizing vocational training as a tool for career development, prolonging their participation in the labor market and adapting them to the labor market.
\end{abstract}

\section{A problem statement}

Older workers' position in the labor market is cause for concern in many countries. Economic crisis has forced many older workers changed their position in the labor market. Encouraging older workers to work longer and fostering their employability have become priorities for policymakers in different countries. Rapid population aging is challenging pension systems.

In 2018 President of the Russian Federation Vladimir Putin signed the Federal law "On Amendments to Certain Legislative Acts of the Russian Federation on the Appointment and Payment of Pensions". This law provides for a gradual increase in the retirement age to 65 and 60 years (men and women, respectively).

According to the United Nations report, the proportion of people over 60 will grow from $12.3 \%$ in 2015 to $14.9 \%$ in 2025 and $21.5 \%$ in 2050 all over the world. It will increase from $23.5 \%$, and in 2015 to $28 \%$, in 2025 and $34.2 \%$, in 2050 in Europe and from $20 \%$ in 2015 to $23.9 \%$ in 2025 and $28.8 \%$ in 2050 in Russia [22].

According to the World Health Organization, older people are people between 60 and 74 years old. The United Nations classifies older person as over 60 years of age. This study examines older workers' employment.

Older workers face ageism, according to researchers of the Milken Institute. They state that older employees tend to be characterized as "slow, unmotivated and out of date" [18].

*Corresponding author: ipcs-profped@yandex.ru 
The law "On Education in the Russian Federation" enshrined the concept of lifelong education, which provides the possibility of realizing the right to education throughout lifespan [12].

In accordance with the demographic situation, it is necessary to solve new tasks and goals in relation to older workers' employment. In this regard, the problem of older workers' participation in vocational training programs is being topical.

Vocational training might be a tool to improve the productivity and employability of older workers.

According to Business dictionary, vocational training is defined as: training that emphasizes skills and knowledge required for a particular job function.

Older workers' vocational training is a field of training focused on the development of the skills necessary for older workers' employment. Vocational training may include general job skills training but is usually directed toward learning the skills necessary for a specific job. Vocational training is usually limited by the processes and knowledge required to a job. Also, older workers' vocational training provides with the knowledge and skills necessary to pursue a selected career. Older workers may participate in vocational training either as students seeking employment or as employees on the job. Older workers' vocational training is often offered to help employees transition into new job duties.

At the same time, the system of vocational training for older workers in Russia is just beginning to develop.

First of all, it should be noted that, vocational training should be adapted to older workers' needs, as well as to the needs of employers and vacancies in the labor market. Also, it is necessary to determine the forms of labor and strategies for promoting employment opportunities in modern socio-economic conditions.

However, at present, this approach is not always implemented, and knowledge of the entire set of social, economic and demographic features of changes in the labor potential of society is required. It is necessary for rational management of labor resources in modern conditions.

\subsection{The objective of the work}

Older workers' employment, labor market participation, job performance, working conditions and work preferences of older workers are considered in the works of both Russian and foreign scientists due to the demographic aging of the population, the shortage of labor resources, and the low level of pension provision in some countries.

Labor activity and extended lifespans in various historical periods were considered in the works by some Russian scientists, such as S.A. Novoselsky, V.V. Paevsky, I.P. Kurkin, V.S. Lukyanov, and A.N. Rubakin.

In the middle of the 20th century, the Institute of gerontology was organized in the USSR. Researchers studied the issues of older workers' employment and a framework to prolong their participation in the labor market.

I.V. Kalinyuk, V.V. Nikitenko, and H.H. Sachuk considered the issues of professional performance, older workers' age-related ergonomics of physical and mental labor in certain industries.

A.G. Solovyova and V.D. Shapiro investigated older workers' motivation to work after the statutory retirement age.

At the end of the 20th century, sociological studies were conducted on older workers' employment due to the changing socio-economic situation in the country and a sharp increase in the number of older workers in the labor market. The obtained data allowed justifying the need to use the labor of older workers in labor market, identifying the main 
factors for older workers' employment and the main directions extending working lives, justifying socio-economic efficiency [10].

Currently, in Russia, there is a growing interest in the problem of older workers' employment and their education, due to changes in the Federal legislation.

It should be noted that not all the data of the conducted sociological research are covered; it makes it difficult to compare the problem of the study. The State report on the situation of older workers in the Russian Federation states that sociological studies were conducted among the older people in many regions of the country, the results were used to determine regional social policy, but the results of these studies were not published.

Thus, in the new socio-economic realities of modern Russian society, the problems of older workers' employment have not been sufficiently studied. The complexity of obtaining statistical data does not allow us to fully analyze and formulate conclusions in the field of work and training of older workers. There are no studies on older workers' vocational training to retain their labor capital. All these problems require be studying and researching.

A great contribution to the development of the theories of gerontology is made by scientists from different countries. They are studying the socio-economic situation of older workers and the impact of demographic aging on labor market.

\section{Materials and the results of the research}

Becker considered older workers' education as an investment in human capital. According to his work, the participation of older workers in the labor market is expected to increase. However, this may be offset by ageism, i.e. employers' unwillingness to hire older workers.

According to research by Larsen and Rosenstock, globalization, digitalization, and technological advances are creating new types of jobs and changing the skills needed for existing work operations. The demand for workers with professional education who have the necessary professional skills will grow. Therefore, many older workers need to develop their basic and professional skills or retrain to improve their position in the labor market. The research shows that the development and improvement of skills throughout the professional career (lifelong learning) is important for older workers' professional needs, especially in workplaces where the requirements for work and competencies are constantly changing [15].

The link between vocational training and reduced early retirement has been documented. There is a lot of research on which groups participate in various forms of competence development, much less is known about the relationship between participation in further vocational training and employment.

A number of studies inform on the impact of older workers' level of education on the employment. Tikkanen and Nihan studied the European experience of teaching older workers and the relationship with age. They concluded that lifelong learning should be made available to all employees. Gris, Krieger, and Mayer studied the retirement age and suggested that lifelong learning can reduce the number of workers retiring earlier than mandatory retirement. Desjardins and Warnke provided an overview of age-related skill profiles and potential factors influencing skill acquisition and loss, both at the individual and population level. Stenberg and de Villena studied whether vocational training promotes or counteracts trends of cumulative advantage over the lifespan in Sweden, the UK, Spain, and Russia, and concluded that modernization of vocational training can reduce social inequality in all this countries. In the UK and Sweden, it tends to expand employment opportunities. Blossfeld, Kilpi-Jakonen, de Villena, and Buchholz studied vocational training in 14 countries, focused on formal education. It increases employment opportunities, although the effect varies significantly between countries in terms of learning and education, and that it has affected income level and employment [18]. 
Triventi and de Villena found that the Nordic countries (Sweden, Denmark, and Finland) demonstrate a lower return on formal adult education than liberal countries. Countries of Northern Europe are characterized by negative returns on formal education and the positive effect of informal learning. This is due to inter-ethnic differences in attitudes to formal education in different countries, formal education is more widespread in the Nordic countries, and the prevalence of vocational training may be inversely correlated with its economic impact.

Stenberg and Westerlund compared education level of workers aged from 42-55 to 6073 and found that vocational training prolong their participation in the labor market after the statutory retirement age. Other studies have also shown that formal adult education increases older workers' earning and employment. They claim that vocational training has a positive impact in terms of increasing participation in the labor market, increasing income and professional status.

There is a problem with analyzing the type of cross-sectional data. It is the fact that there is a statistical correlation between participation in vocational training and different types of work. In truth, it does mean that higher wages and a higher probability of employment are the result of vocational training. However, there is evidence that participation in vocational training is important for employment. At the same time, there is a need to know more about the causal relationships and mechanisms underlying statistical variation, and more analysis based on longitudinal data is needed to obtain this information.

Detailed micro-level data is needed to study the differences in older workers' employment between age group 60+ who participated in vocational training and those ones who did not do it.

The research demonstrates that vocational training effect on career mobility, as well as motivates older workers to work after the statutory retirement age.

Vocational training is positive for older workers, providing access to new knowledge or new skills that can contribute to job orientation and job satisfaction. The results suggest that increasing the volume of vocational training make a significant contribution to the overall labor supply.

The interest in vocational training is raised due to the expected aging of the population, which will lead to the need to extend the working life of older workers. All levels of education have a positive impact on employment. Vocational training opportunities for workers $60+$ can make it easier for older workers to actively participate and stay longer in the labor market. Accordingly, extending working life through vocational training may reduce some of the problems associated with an aging population.

The research is based on the principles of integrity, consistency, and historicism.

The research methods are a comprehensive analysis that includes socio-demographic, socio-gerontological, statistical-economic, sociological, and socio-psychological approaches, which made it possible to increase the objectivity of the results of the work. The structural and functional method provided an opportunity for an essential and functional study of older workers' employment, and helped determine the place and role of this phenomenon in sociological knowledge. The research based on sociological methods of obtaining, processing and interpreting information, including the method of observation and surveys.

The purpose of this study is to analyze the impact of vocational training on older workers' employment.

The following tasks have to be solved:

- to determine the impact of vocational training on older workers' employment;

- to identify mechanisms to promote employment opportunities for older workers.

The achievement of this goal will contribute to the modernization of vocational training system in matters of extending older workers' employment. 
The problem of older workers' employment remains partially unresolved. One of the reasons is negative stereotypes regarding the employment of this category of employees on the part of employers. Not all older people are able to exercise their right to work. According to the Federal State Statistics Service, in the period 2014-2018, more than 196 thousand workers aged $60+$ would like to prolong their participation in the labor market. They are looking for work and are ready to work.

Older workers' employment is an urgent problem of modern society. The economic efficiency of using older workers' labor remains open to controversy. Russia, as well as the world's leading countries, is developing a set of measures at the state level to extend the working life of older workers.

Often, the chances of getting a job for older workers are reduced due to insufficient qualifications and lack of necessary skills. Therefore, an integral element of measures to extend the working life of older workers should be their professional reorientation, training and retraining. Vocational training is one of the mechanisms to prolong older workers participation in the labor market and to develop necessary skills. In practice, organizations providing vocational training programs for older workers are rare and isolated phenomenon. Nevertheless, modern society is gradually coming to understand that it is necessary to create conditions for older workers' vocational training. The current socioeconomic situation leads to the fact that older workers will more often participate in vocational training programs.

Regulatory documents have been adopted at the legislative level, and amendments have been made to the Criminal Code of the Russian Federation to solve this problem,

In 2012 - 2014, sociological surveys were conducted to determine the older workers' educational needs to actively participate in the labor market. It included 6,300 people of pre-retirement age.

According to the survey, the employment process is difficult due to:

- lack of vacancies $(45,2 \%)$;

- insufficiently high level of wages (23\%);

- inappropriate working conditions $(13.7 \%)$;

- age and health restrictions $(11.4 \%)$;

- lack of required qualification $(6.7 \%)$ [4].

The survey of respondents revealed the limited choice of employment for older workers. The problem of lack of required qualifications, lack of vacancies, as well as low wages can be solved by including older workers in vocational training, taking into account the role of older people in the educational process as both trainees and teachers. Training can be a tool for improving the productivity and employment of older workers, as it can refresh human capital and reduce the productivity gap.

In Russia, only about $30 \%$ of older workers are covered by formal and non-formal education. While in the countries with the highest indicator, the share of students in this age group reaches $70-80 \%$. $15 \%$ of the population of Russia is engaged in vocational training, lower rates are recorded only in Turkey, Greece and Romania. 20.8\% of the population aged 55-64 has a higher education.

According to Rosstat, the level of education of older workers corresponds to the educational level of the entire population. The elderly population generally has sufficient potential to participate fully in the labor force. However, this potential is not fully realized in practice. According to the data of the Federal State Statistics Service in 2014, 42\% of older people with a specialty confirmed by a diploma or certificate worked at position did not correspond to their specialty; as a result, $33.7 \%$ of older workers rated their professional satisfaction with their work unsatisfactorily or not completely satisfactory. In 2014, 2/3 of older workers who had the main job that did not correspond to their specialty did not have 
the opportunity to participate in vocational training or retraining. Only $1.1 \%$ of older workers participated in different types of vocational training [5].

Our survey in the Sovetsky district of Samara revealed that $17 \%$ of respondents would like and are ready to participate in vocational training; $34 \%$ - found it difficult to answer; $28 \%$ - have improved their professional skills and participate in vocational training in the workplace over the past 5 years; $11 \%$ - said that they do not need to improve their skills at the moment. The survey included 137 workers aged 60+. A comparative analysis of the data revealed that older workers still rarely participate in vocational training.

Among older workers, significantly lower participation in vocational training was found for people with lower annual income, lower education levels, temporary employment, workers or employees, as well as those working in the private sector.

The survey identified three main types of barriers to participation in vocational training: situational, institutional, and dispositional [3].

Situational barriers arise due to the current life situation, for instance, too busy at work, financial constraints, family responsibilities, and health problems.

Institutional barriers consist of established practices and procedures that exclude or discourage participation, such as high tuition fees, entry requirements, limited course offerings, and courses offered at inconvenient times or locations.

Dispositional barriers include attitudes and opinions about learning, as well as selfperception as a student.

According to the survey, older workers who did not participate in vocational training despite their need or desire, identified:

- situational barriers $(45 \%)$,

- dispositional barriers (33\%),

- institutional barriers (17\%).

In particular, the respondents mentioned lack of trust, interest or motivation is an important obstacle to vocational training.

To overcome these barriers, it is necessary to develop the mechanisms for prolonging working lives and extending older workers' employment.

The most important mechanisms have been identified:

- theoretical and practical validity of participation of older workers in vocational training as both trainees and trainers;

- development of special vocational training programs for older workers;

- providing training expenses for older workers

- using of modern information technologies;

- distance learning;

- establishing the Institutes of vocational training for older workers [11].

To our point of view, it is important to assist older workers to participate in vocational training. It can be positive for older workers by providing access to new knowledge or new skills that can contribute to job orientation and job satisfaction. According to researches of skills in the future, the demand for people who participated in vocational training will grow. Therefore, older workers need to develop their basic and professional skills and participate in vocational training programs, in order to improve their position, actively participate and stay longer in the labor market.

\section{Conclusions}

Despite the growth in the employment rates of older workers over the past decade in many countries, it is noted that the potential to increase these rates further. Promoting employment opportunities for older workers requires new mechanisms which help to overcome the situational, the institutional, and the dispositional barriers. Older workers' 
employment requires creating a working environment adapted to older workers' professional needs to enable them to prolong their participation in the labor market. The low coverage of older workers participating in vocational training programs can be overcome by popularizing vocational training as a tool for career development, prolonging their participation in the labor market and adapting them to the labor market. Most countries provide opportunity to vocational training for older workers. We suppose that it is necessary to bring vocational training programs closer to older workers' needs to prolong their working life. Governments can play a role by providing no fee vocational training programs for older workers. Companies can also play a role with measures aimed at stimulating older workers' vocational training. Employers should be consulted regarding the design of vocational training programs and their curricula. National law should advocate the concept of lifelong education, which provides the possibility of realizing the right to education throughout lifespan. Older workers' participating in vocational training programs could prevent the end of their employment. Some companies also specifically recruit older workers. The implementation of vocational training among older workers will be successful if vocational training is a type of professional education. Initiatives that inform older workers about current labor market opportunities and the benefits of vocational training may therefore be crucial supporting initiatives to the extension of vocational training. We believe that the cultural background should be taken into account in the design of vocational training programs. It should be considered to train the decisionmaking abilities of older workers by integrating broader career and educational guidance services in vocational training. Finally, research into the effects of vocational training would benefit from the availability of better data and a suitable program. The generation of representative survey data, in particular longitudinal data with a full set of individual characteristics is essential. Vocational training programs should be accompanied by a systematic collection of evaluation data.

To sum up, the further development of vocational training should take into account the main challenges in particular countries in order to be successful. These measures could be crucial in attracting and retaining older workers.

\section{References}

1. Ancient and active: are older staffs in the workplace to stay?, access mode: https://www.ft.com/content/d651e552-d30e-11e9-8d46-8def889b4137

2. G.S. Becker, Investment in human capital: A theoretical analysis. Journal of Political Economy 70, access mode: https:// doi.org/10.1086/258724

3. Demographic Yearbook of Russia: 2015, access mode: http://www.gks.ru/bgd/regl/B15_16/Main.htm (M.: Rosstat, 2016)

4. Department for Work and Pensions. Annual Report and Accounts. 2014-15, access mode:

https://www.gov.uk/government/uploads/system/uploads/attachment_data/file/445952 /dwp-annual-report-and-accounts-2014-to-2015-print.pdf (2015)

5. Federal Law "On Education in the Russian Federation" N 273-FZ dated December 29, 2012 as amended in 2019. access mode: http://zakon-ob-obrazovanii.ru (2012)

6. J. Field, Well-being and happiness: Inquiry into the Future for Lifelong learning (IFLL) (2019)

7. B. Findsen, Derivative and indigenous modes in older adult education in Aotearoa/New Zealand. In B. Merill \& P. Armstrong (Eds.), Looking back, looking forward: learning, teaching and research in adult education past, present and future, 
Proceedings from the $40^{\text {th }}$ Annual SCUTREA conference held at the University of Warwick, 141-147 (6-8 July, Coventry, 2010)

8. Follow-up to the International Year of Older Persons: Second World Assembly on ageing. Report of the Secretary-General, 19 July 2013, United Nations, access mode: www.un.org/development/desa/ageing/international-day-of-older-persons-homepage (2013)

9. T. Gries, S. Jungblut, T. Krieger, H. Meier, Statutory retirement age and lifelong learning (2006)

10. Labor Force Survey. 2016 year. Statistical Bulletin, access mode: http://www.gks.ru/free_doc/doc_2017/bul_dr/trud/ors-2017-1kv.rar (2016)

11. E.S. Lapshova, Age and Language in Russia, Foreign language education in a multicultural environment - materials and reports of the XXIV scientific-practical conference of the National Association of English language teachers (NATE 2018), 96-98 (Samara, 2018)

12. E.S. Lapshova, S.V. Nikolaev, The influence of vocational training, retraining on the labor activity of older people, Bulletin of the Samara State Technical University. Series: Psychological and pedagogical sciences, 4 (44), 137-149 (Samara, 2019).

13. Law 3191/2003. The National System of Connection of Vocational Education and Training with Employment (N.S.C.V.E.T.), A (258), 4497-4508

14. Law 3789/2010. Development of Lifelong Learning and Other Regulations, A (163), 3401-3428

15. On the implementation of the state program of the Russian Federation "Promotion of employment of the population" in 2015, access mode: http://www.rosmintrud.ru/docs/mintrud/migration/62

16. Organization of Vocational Education and Training (O.V.E.T.). Training Regulation. Guardian of Museums and Archaeological Sites (Thessaloniki: O.V.E.T., 2009).

17. Russia in numbers. M.: Rosstat. 511. (2017).

18. Russian statistical yearbook. Stat. Sat. M.: Rosstat, access mode: http://www.gks.ru/bgd/regl/b16 13 (2017)

19. V.D. Shapiro, Retired man: social problems and way of life. (Moscow, 1980)

20. A. Stenberg, O. Westerlund, Flexibility at a cost - Should government stimulate tertiary education for adults?, Journal of the Economics of Ageing, 7, 69-86 (2016)

21. Strategy of actions in the interests of citizens of the older generation in the Russian Federation until 2025. Approved by the order of the Government of the Russian Federation, 164-r, access mode: http://www.gks.ru (05.02.2016)

22. D.A. Schon, Educating the reflective practitioner: Toward a new design for teaching and learning in the professions (San Francisco, CA: Jossey Bass., 1987)

23. A. Stenberg, O. Westerlund, Flexibility at a cost - Should government stimulate tertiary education for adults? Journal of the Economics of Ageing, 69-86. (2016)

24. United Nations Principles for Older Persons. Adopted by General Assembly resolution 46/91 of 16 December 1991, access mode: http: //www.un.org/ru/documents/decl_conv/conventions/oldprinc.shtml

25. M. Welton, Civil society. In L.M. English (Ed.), International Encyclopedia of adult education, 100-101 (New York: Palgrave Macmillan, 2005)

26. A. Withnall, Improving learning in later life (London: Routledge, 2010) 
27. A. Withnall, V. McGivney, J. Soulsby, Older people learning: Myths and realities (Leicester: NIACE, 2004) 